Document downloaded from:

http://hdl.handle.net/10251/116573

This paper must be cited as:

Canto-Perello, J.; Morera Escrich, JL.; Martín Utrillas, MG.; Curiel-Esparza, J. (2018). Restoration prioritization framework for roadway high cut slopes to reverse land degradation and fragmentation. Land Use Policy. 71:470-479. doi:10.1016/j.landusepol.2017.11.020

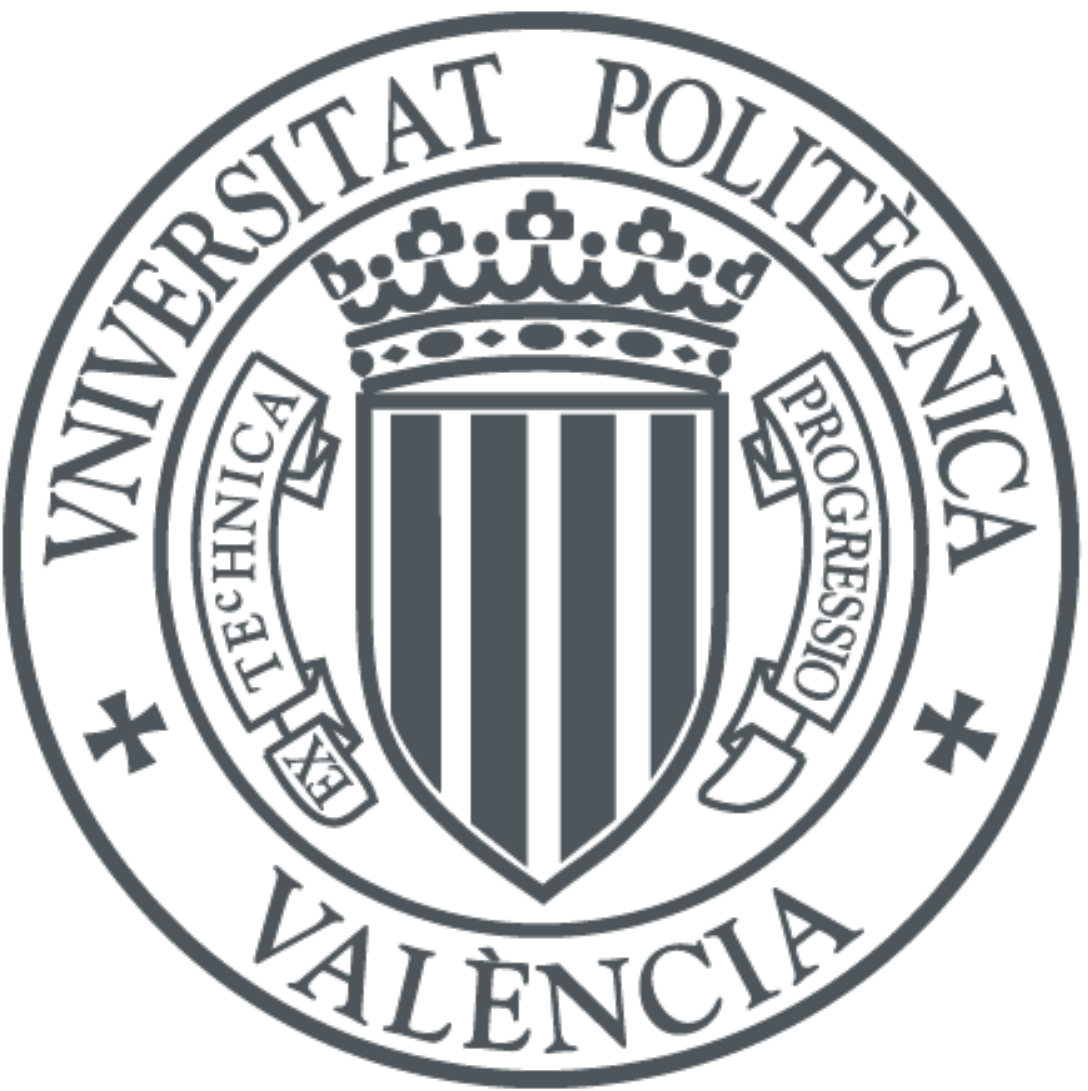

The final publication is available at

http://doi.org/10.1016/j.landusepol.2017.11.020

Copyright Elsevier

Additional Information 


\title{
Restoration prioritization framework for roadway high cut slopes to reverse land degradation and fragmentation
}

\begin{abstract}
Land degradation is one of the most critical global environmental threats. The EU Biodiversity Strategy to 2020 has appointed land degradation and ecosystems fragmentation caused by transport infrastructures as crucial threats to biodiversity. Implementing environmental criteria in roadway project conception phase for restoring large cut slopes will prevent this threat. There is a lack of decision support systems to implement environmental criteria in the decision making procedure to restore high cut slopes. The major difficulties have been building consensus and ensuring traceability and transparency from the panel of experts. This paper presents a hybrid framework capable of dealing with environmental criteria and also with conventional territorial and economic criteria. The decision support procedure combines the Analytical Hierarchy Process with the Delphi technique and the VIKOR procedure. The experts' consensual decision-making process is properly documented, unambiguous and verifiable. The results of this study yielded that the functional and environmental criteria are the key factors in the decision-making process of large cut slope restoration projects. And it has been found the suitability of the cut-and-cover tunnels despite their higher cost and complexity of its construction.
\end{abstract}

Keywords: Cut slopes, land degradation, ecosystem fragmentation, AHP, VIKOR 


\section{Introduction}

In the report 'Our life insurance, our natural capital: a European Union (EU) biodiversity strategy to 2020', the European Parliament stated that biodiversity degradation is one of the most critical global environmental threats (EUPAR, 2012). Biodiversity and landscape management have become crucial pillars of EU policies (Cervelli et al., 2017). There are continued and growing pressures on Europe's biodiversity: land-use change, over-exploitation of biodiversity and its components, transport infrastructures, spread of invasive alien species and pollution among others. In addition, indirect drivers such as population growth, little awareness about biodiversity and scarcity of environmental criteria in decision making, are also taking a heavy toll on biodiversity. These actions result in the degradation of landscapes with important consequences for the provision of ecosystem services. In this context, land degradation and ecosystems fragmentation caused by transport infrastructures are key threats for biodiversity (EEA, 2015). Regarding this issue, the EU's strategy has appointed the objective of restoring at least 15 per cent of degraded ecosystems before 2020 (EUPAR, 2012). Thus, EU member states should restore fragmented habitats by existing roadways in order to accomplish the established goals before 2020. Habitat fragmentation and land degradation by roadways has been studied from different points of view by many researches, either directly on the roadway or indirectly, through the study of green corridors for habitat fragmented connection (Shapira et al., 2013). It is also necessary to study the restoration under the action $6 \mathrm{~b}$ of EU Biodiversity Strategy to 2020, that is, developing Green Infrastructure including from ecoducts to stepping stones in order to reconnect artificially divided natural areas by roadways (IENE - Infra Eco Network Europe Stering Committee, 2013). Making optimal decisions in the project conception phase of infrastructure will improve sustainability. Decision-makers need to use defined and measurable procedures (Hunt et al., 2013; Laurila-Pant et al., 2015). This research work has focused on implementing environmental criteria in the decision making of roadway project assessment to restore existing large cut slopes. There is a lack of decision support frameworks to implement environmental criteria in the selection of strategies to restore high cut slopes using a panel of experts and capable of achieving consensus in the final solution.

This paper presents a hybrid model capable of dealing with environmental criteria together with traditional territorial and economic criteria. The decision support system proposed is a hybrid method combining the Analytical Hierarchy Process (AHP) with the Delphi method and the VIKOR technique. The traceability and transparency of the decision support system are essential for ensuring a fair procedure. All stages have been duly documented to guarantee traceability and transparency (EUDirective, 2014). The AHP method allows the utilization of linguistic variables (Saaty, 2008). And therefore, this technique is very suitable for complex decision problems in which intangible factors cannot be neglected (Martin-Utrillas et al., 2015; Palmisano et al., 2016). The different indicators implemented will be environmental, functional, territorial and economic criteria. All of them, with their different weights, will be analyzed in relation to the possible restoration alternatives to develop. The AHP is based on paired comparisons from panelists and is capable of dealing with intangible criteria. Participatory methods should play an important role in combating land degradation (Tikkanen et al., 2016). The AHP methodology is a suitable technique for structuring the relevant knowledge in complex 
multicriteria problems (Giri et al., 2016). The Delphi method has been used to collect data from the panel of experts. The Delphi technique is performed to facilitate an efficient panel of experts' dynamic process. Finally, the VIKOR method obtains the compromise solution in decision problems with conflicting and no commensurable criteria that is the closest to the ideal (Opricovic and Tzeng, 2007). The alternatives are evaluated according to all established criteria, and the achieved compromise solution provides a maximum utility of the majority, and a minimum individual regret.

\section{Decision hierarchy structure analysis}

Using anonymous questionnaires, the Delphi method gathers the experts' opinions on the criteria and restoration strategies studied (Curiel-Esparza et al., 2016). For this analysis, a panel of twelve experts has been chosen among environmental and transport engineers with recognized competence and knowledge in the field under study. Each expert could provide additional restoration strategies or criteria/subcriteria, if considered. Afterwards, their proposals will be returned to them for new reconsideration. With this anonymous feedback, experts with different points of view help to facilitate the understanding of the issues discussed, allowing a consensus to be reached between all of them. In addition, it is also possible to remove the least significant criteria and restoration strategies for integration of linear transport infrastructure into the surrounding landscape.

To achieve the objective, several factors have been proposed: perceptual environment, physical environment, together with functional, territorial and economic factors. These core factors were further decomposed in eleven subfactors which were used for the analysis (see Figure 1). The transport infrastructures should always be considered from the point of view of the sustainability (Canto-Perello and Curiel-Esparza, 2006; CantoPerello et al., 2009; Rajak et al., 2016). The ecosystem health and sustainability are key endpoints and should be desired goals to be taken into account when developing the decision support system (Costanza, 2012; Curiel-Esparza et al., 2015). The stability of high cut slopes has not been a criterion in the proposed method as it is mandatory to guarantee the safety of all the restoration strategies proposed (Sun et al., 2012, Sun et al., 2013). They are described as follows:

- Perceptual environment (PEE), i.e. operational environment that humans are conscious of through organic-sensory. It can be divided into two subfactors. The first one, landform impact (LA), because roads have an effect on the different variables affecting the generation of landscape (Liu et al., 2008). The second subfactor is the visual impact ( $\mathrm{VI}$ ) on potential observers. The roadway should be coordinated with the landscape structure (Hu et al., 2012). An optimal cut slope restoration can ensure healthy environments and, as a consequence, physical and psychological health benefits to the people living within them (Tzoulas et al., 2007).

- Physical environment (PHE), which is structured in two subfactors: abiotic environment $(\mathrm{AB})$ and biotic environment $(\mathrm{BI})$. Abiotic subfactor takes into account many environmental indicators including local hydrology and geological conditions. In cut slope case and especially when existing water-limited conditions, it is important to consider geotechnical and geological parameters, but also erosive phenomena and 
soil loss, because of the strong relationship between rill erosion and vegetation (Moreno-de las Heras et al., 2011, Lee et al., 2013). For the second subfactor, biotic environment, the existence of great cut slopes enhances habitat loss. Furthermore, Benítez-López et al. (2010) have shown that the populations of mammals and birds are reduced as the distance to infrastructure becomes smaller. The effect on bird populations extended over distances up to about one kilometer, and for mammal populations up to about five kilometers.

- Functional factor (FUN), for which two subfactors have been developed. The first one, road safety (SA), is an important indicator for selecting the optimal solution in hilly lands (Fu et al., 2011). Calvi et al. (2012) have studied the effects of tunnels on driving performance that should be taking into account in the cut-and-cover tunnels. On the other hand, driving impact on users while construction (US) has been considered.

- Territorial factor (TEC) is divided into three subfactors: territorial planning coordination (TE), horizontal occupation area (HO) and ecosystem fragmentation (FR). Yu et al (2012) have pointed out the requirements of territorial sustainable development are intertwined with the problems of land use intransigence, fragmentation and deterioration of natural systems. In addition, the European Commission have developed guidelines for the choice of different types of fauna passages (luell et al., 2003). These guidelines are based on landscape, habitats and target species, which are the mean factors within the ecosystem fragmentation problem.

- Economical factor (ECO), structured in two subfactors, such as construction costs (CO) and maintenance costs (OM).

On the other hand, there are different possible restoration strategies for integration of linear transport infrastructures into the surrounding landscape. Moreover, restoration of cut slopes is a wider problem that includes different territorial alterations. In ecosystem fragmentation problem, a recent study shows that the tendency has been to design and build underpasses (95.4\%) instead of overpasses (Sorolla and Solina, 2013). Only 1.6\% of underpasses were specific for wildlife, whereas for overpasses, near $45 \%$ were ecoducts and specific wildlife passages. Dry ledges can be useful to favor certain species that could use different types of modified drainage culverts and similar structures (Bager and Fontoura, 2013). Usually, the economic criterion is the key factor in selecting the final solution. And therefore, the enhancement of drainage culverts is always less expensive than other solutions. However, there is a lack of knowledge on the effectiveness of dry ledges in drainage pipes, even when combining fencing for vertebrates (Villalva et al., 2013). The objective should be to avoid the economic factors as the decisive excluding other criteria.

Different strategies have been proposed to reach the goal of cut slopes restoration. These strategies allow to solve the problem of territorial integration of cut slopes. Restoration strategies should ensure the sustainability of the restoration design and achieve synergy between stabilization and landscape integration of the slopes avoiding territorial fragmentation (Bortoleto et al., 2016). The proposed decision support technique is able of dealing with this complex problem and its synergistic factors. The following six restoration strategies for large road cut slopes are analyzed:

- Rock outcrops generation (ROO): This strategy combines, on one hand, a soft solution on the cut-slope acting on the shape for becoming irregular, naturalizing it to avoid visual impacts. And, specially, allowing vegetation to grow up in order to create 
little habitats. For getting better aesthetic effect, it is also possible rounding off the tops of the cuttings. On the other hand, this solution must be accompanied with wildlife-crossing points designed to minimize barrier effect (Mata et al., 2008).

- Slopes with bio-engineering measures (SBI): It consists in placing on cut slopes different possible bio-engineering elements for favoring plants growing up and, thus, improving the stability of the slopes using their roots (Garg et al., 2014). At the same time, as before, wildlife-crossing points must be projected to minimize barrier effect.

- Terracing-cutting (TER): One step more in the control of the soil erosion and better restoration consists in terracing the slopes (Dumbrovský et al 2014). It is more expensive than the previous solutions, but it has environmental benefits over them such as growing up trees and other woody species. Also, this strategy needs wildlifecrossing points to decrease barrier effect.

- Wildlife overpass (WOV): The proposed strategy focuses on constructing an overpass which connects the cut slopes verges (Olsson et al., 2008). Overpasses are located in points where animals usually cross, and adapted to the affected species.

- Wildlife underpass (WUN): This restoration strategy includes different underpass structures as, for example, jacked tunnels adapted for animals' exclusive use or jointuse ( $\mathrm{Ng}$ et al., 2004).

- Cut-and-cover tunnel (CUT): This strategy for restoring the high cut slope consists in building a landscape bridge (luell et al., 2003). It could be considered an overpass or an underpass, but longer than those and covering an important section of the road. This is the key difference with WOV and WUN strategies.

Considering all these criteria and restoration strategies, the hierarchy structure for implementing AHP is shown in Figure 1.

\section{Construction of pairwise comparison matrix}

According to the Delphi process, a questionnaire is sent to the panel of experts. Each expert assesses the main factors and restoration strategies. The Delphi technique is used to collect data from the expert panel and to allow their interaction with anonymous feedback (Curiel-Esparza et al., 2016). In the literature, the optimum number of experts per panel is between eight and twelve panelists to successfully undertake the Delphi method (Novakowski and Wellar, 2008). AHP decomposes a complex situation in a structured hierarchy. This hierarchy is needed to construct the comparison matrices. Afterwards, the comparison matrices are used to calculate the priorities and to analyze the consistency. A 9-pointscale is applied to evaluate the main criteria and subcriteria through the questionnaire, and to assess the proposed restoration strategies with respect to the overall goal (Saaty, 2012). Firstly, each expert performed a pairwise comparison to indicate their preference for each criterion and subcriterion. With respect to the overall goal, each of the twelve experts have completed this ten items questionnaire to assess the main criteria for great road cut-slopes restoration:

1. How important is Perceptual environment (PEE) when it is compared to Physical environment (PHE)?

2. How important is Perceptual environment (PEE) when it is compared to Functional criteria (FUN)? 
3. How important is Perceptual environment (PEE) when it is compared to Territorial criteria (TEC)?

4. How important is Perceptual environment (PEE) when it is compared to Economical criteria (ECO)?

5. How important is Physical environment (PHE) when it is compared to Functional criteria (FUN)?

6. How important is Physical environment (PHE) when it is compared to Territorial criteria (TEC)?

7. How important is Physical environment (PHE) when it is compared to Economical criteria (ECO)?

8. How important is Functional criteria (FUN) when it is compared to Territorial criteria (TEC)?

9. How important is Functional criteria (FUN) when it is compared to Economical criteria (ECO)?

10. How important is Territorial criteria (TEC) when it is compared to Economical criteria (ECO)?

In addition, each of the twelve experts have completed this seven items questionnaire to assess the subcriteria as follows:

1. Regarding the PEE criterion:

How important is Landform impact (LA) when it is compared to Visual impact $(\mathrm{VI})$ ?

2. Regarding the PHE criterion:

How important is Abiotic environment $(A B)$ when it is compared to Biotic environment $(\mathrm{BI})$ ?

3. Regarding the FUN criterion:

How important is Road safety (SA) when it is compared to Driving impact on users while execution (US)?

4. Regarding the TEC criterion:

How important is Territorial planning coordination (TE) when it is compared to Horizontal occupation area $(\mathrm{HO})$ ?

How important is Territorial planning coordination (TE) when it is compared to Ecosystem fragmentation (FR)?

How important is Horizontal occupation area $(\mathrm{HO})$ when it is compared to Ecosystem fragmentation (FR)?

5. Regarding the ECO criterion:

How important is Construction costs $(\mathrm{CO})$ when it is compared to Maintenance costs (OM)?

The Table 1 shows the results from the elicitation process applied to the panel of twelve experts using a 9-point scale. Each panelist performed a pairwise comparison to show its preference for each criterion and subcriterion. Higher values indicate a higher preference of one of the paired criteria or subcriteria over the other. If the first criteria or subcriteria is preferred, the value is the corresponding integer. If the second criteria or subcriteria is preferred, the inverse of the integer is applied. Secondly, individual judgments for criteria and subcriteria of each expert are aggregated using the geometric mean value (Dong et al., 2010). The matrix C obtained from experts' judgment aggregation to assess criteria is given by: 


$$
C=\left[\begin{array}{lllll}
1.0000 & 0.4581 & 0.5485 & 1.0538 & 1.4901 \\
2.1832 & 1.0000 & 0.9124 & 1.7111 & 1.8429 \\
1.8233 & 1.0960 & 1.0000 & 2.2972 & 2.4569 \\
0.9490 & 0.5844 & 0.4353 & 1.0000 & 0.9666 \\
0.6711 & 0.5426 & 0.4070 & 1.0345 & 1.0000
\end{array}\right]
$$

The priority vector $(\omega)$ is the eigenvector for the maximum eigenvalue $\left(\lambda_{\max }\right)$ of $\mathrm{C}$ according to Saaty (2012). To calculate this priority vector, the linear system $C \cdot \omega_{C}=\lambda$. $\omega_{C}$ must be solved using $\operatorname{det}(C-\lambda \cdot I)=0$. Hence, the criteria's priority vector is as follows:

$$
\omega_{C}=\left[\begin{array}{lllll}
0.1564 & 0.2717 & 0.3030 & 0.1399 & 0.1291
\end{array}\right]
$$

One of AHP's advantages is that the inconsistency of the experts' judgements can be measured. The evaluation of the consistency of the judgements is performed by an index called consistency ratio (CR). The maximum threshold of the $\mathrm{CR}$ is a function of the order of the matrix. CR is calculated from the following expression,

$$
C R=\frac{C l}{R C l}
$$

The consistency index $(\mathrm{Cl})$ is calculated from the following expression,

$$
C l=\frac{\lambda_{\max }-n}{n-1}
$$

The $\mathrm{RCl}$ value is fixed and depends on the order of the matrix, see Table 2. For instance, the matrix $\mathrm{C}$ obtained from experts' judgment aggregation to assess criteria has order equal to five, and therefore, the CR value should be equal or below 0.1 to be considered acceptable. Otherwise, the answers must be reviewed. The same process is followed for subcriteria. For (1), $\lambda_{\max }=5.0311, \mathrm{Cl}=0.0077$ and $\mathrm{CR}=0.0069<0.1$. As an example, priority vector and consistency analysis of the pairwise comparison matrix (SC TER) for three Territorial subcriteria is shown.

$$
S C_{T E R}=\left[\begin{array}{ccc}
1.0000 & 1.085 & 0.8525 \\
0.9021 & 1.0000 & 0.5484 \\
1.1730 & 1.8236 & 1.0000
\end{array}\right]
$$

The priority vector of the pairwise comparison matrix for the three Territorial subcrieteria is as follows,

$$
\omega_{S C_{T E R}}=\left[\begin{array}{lll}
0.3206 & 0.2584 & 0.4210
\end{array}\right]
$$

For (5), $\lambda_{\max }=3.0127, \mathrm{Cl}=0.0063$ and $\mathrm{CR}=0.0122<0.1$.

So, finally, composing the results for criteria and subcriteria, the global value for each of them is obtained and shown in Table 3. 


\section{Evaluating restoration strategies according to criteria}

For each subcriteria, the experts have indicated their preference between pairs of restoration strategies. Following the experts' assessment of restoration strategies for each of the eleven established subcriteria, the next step is to calculate the priority of restoration strategies with respect to all of them. A pairwise comparison matrix for the restoration strategies is constructed using the geometric mean value obtained from the experts' judgments. Later, the eigenvector is calculated in order to determine the priority vector, and also a consistency analysis is undertaken using the maximum eigenvalue for each case. For instance, the following landform impact matrix (LA) shows the pairwise comparison matrix for the landform impact subcriterion analysis of strategies.

$$
L A=\left[\begin{array}{llllll}
1.0000 & 1.4066 & 0.8210 & 1.5020 & 1.1981 & 0.6996 \\
0.7109 & 1.0000 & 0.8697 & 1.1677 & 1.1663 & 0.5887 \\
1.2181 & 1.1498 & 1.0000 & 1.2721 & 1.1608 & 0.5992 \\
0.6658 & 0.8564 & 0.7861 & 1.0000 & 0.7596 & 0.5223 \\
0.8347 & 0.8574 & 0.8614 & 1.3164 & 1.0000 & 0.5325 \\
1.4294 & 1.6985 & 1.6690 & 1.9147 & 1.8779 & 1.0000
\end{array}\right]
$$

A matrix for each subcriterion is obtained from the experts' judgements using the geometric mean aggregation procedure as before. The priority vector of each pairwise comparison matrix is calculated using the eigenvector method and a consistency analysis is performed as shown in Table 4. The priority matrix (PM) with the priority vectors for the six restoration projects with respect to each subcriterion is

$P M=\left[\begin{array}{lllllllllll}0.1729 & 0.1626 & 0.2190 & 0.1783 & 0.1250 & 0.2619 & 0.1345 & 0.1345 & 0.0993 & 0.3340 & 0.3349 \\ 0.1440 & 0.1555 & 0.2419 & 0.1635 & 0.1421 & 0.2407 & 0.1578 & 0.1788 & 0.1156 & 0.1993 & 0.1385 \\ 0.1683 & 0.1606 & 0.1639 & 0.1251 & 0.1589 & 0.1801 & 0.0961 & 0.0899 & 0.0930 & 0.1955 & 0.2293 \\ 0.1214 & 0.1214 & 0.1022 & 0.1632 & 0.1816 & 0.0996 & 0.1537 & 0.1760 & 0.1843 & 0.0938 & 0.1093 \\ 0.1408 & 0.1517 & 0.1085 & 0.1875 & 0.1969 & 0.1321 & 0.2350 & 0.2401 & 0.2213 & 0.1079 & 0.1117 \\ 0.2527 & 0.2480 & 0.1646 & 0.1824 & 0.1955 & 0.0856 & 0.2229 & 0.1807 & 0.2865 & 0.0695 & 0.0763\end{array}\right]$

These priority vectors and the global weights for each criteria and subcriteria are used as input to the VIKOR method for the evaluation of the most suitable strategy of restoration.

\section{Evaluating the priorities using VIKOR method}

The VIKOR method has been used to evaluate the priorities for the restoration strategies and to guarantee consensus on the project selected (Opricovic, 2009). This technique selects the strategy which is the better compromise solution among all the studied restoration projects, ranking all of them by measuring the closeness of each restoration strategy with respect to the most suitable project. The method ranks the strategies for restoring high cut slopes $\mathrm{H}_{\mathrm{i}}$ according to the value of three scalar indicators $(\mathrm{S}, \mathrm{R}$, and Q) to be computed for each project. The minimum $S$ value indicates the maximum utility for the majority, while the $R$ value provides the minimum individual regret for the opponent. The indicators $S$ and $R$ are combined to compute the $Q$ value in order to achieve the compromise solution and to ensure consensus. 
Finally, the two requirements of acceptable advantage and stability have been verified. The six restoration projects have been prioritized according to the five criteria and eleven subcriteria. The procedure ranks the projects by the values of $Q$, obtained from the matrix of the eigenvectors shown in (7). For each subcriterion, the values of $f_{j}^{*}$ and $f_{j}^{-}$are computed. These elements $f_{i j}$ are the transpose of the priority vectors matrix shown in Table 5. For each of the eleven subcriteria, the best $f_{j}^{*}$ and worst $f_{j}^{-}$assessments among all the restoration strategies are determined; $f_{j}^{*}=\max \left(f_{i j}, j=1, \ldots, 6\right), f_{j}{ }^{-}=\min \left(f_{i j}, j=1\right.$, $\ldots, 6)$, if the $i$-th function is benefit type; $f_{j}^{*}=\min \left(f_{i j}, j=1, \ldots, 6\right), f_{j}^{-}=\max \left(f_{i j}, j=1, \ldots, 6\right)$, if the $i$-th function is cost type. Finally, the indicators $S, R$ and $Q$ are computed as follows:

- $S_{j}$ (weighted and normalized Minkowski norm for $p=1$, city-block or Manhattan distance) that represents the utility measure for each restoration strategy:

$$
S_{j}=\sum_{i=1}^{n} w_{i} \frac{\left(f_{i}^{*}-f_{i j}\right)}{\left(f_{i}^{*}-f_{i}^{-}\right)}
$$

Where $w_{i}$ is the global weight of each subcriterion shown in Table 4. City-block or Manhattan distance computes the absolute differences between coordinates of two objects.

- $\mathrm{R}_{\mathrm{j}}$ (weighted and normalized Minkowski norm for $\mathrm{p}=\infty$, infinity norm or Chebyshev distance) that represents the measure of regret for each restoration strategy:

$$
R_{j}=\max _{i}\left\{w_{i} \frac{\left(f_{i}^{*}-f_{i j}\right)}{\left(f_{i}^{*}-f_{i}^{-}\right)}\right\}
$$

- Compute the values $Q_{j}, j=1,2, \ldots, 6$, by the relation:

$$
Q_{j}=v \cdot \frac{\left(S_{j}-S^{*}\right)}{\left(S^{-}-S^{*}\right)}+(1-v) \cdot \frac{\left(R_{j}-R^{*}\right)}{\left(R^{-}-R^{*}\right)}
$$

The meaning of $S^{*}, S^{-}, R^{*}$, and $R^{-}$is:

$$
\begin{aligned}
& S^{*}=\min _{j} S_{j} \\
& S^{-}=\max _{j} S_{j} \\
& R^{*}=\min _{j} R_{j} \\
& R^{-}=\max _{j} R_{j}
\end{aligned}
$$

where $v$ is the priority for the strategy of maximum group utility and $(1-v)$ is the priority of the individual regret. If the compromise solution is sought to be achieved by consensus, $v$ value should be set to 0.5 . In addition, a sensitivity analysis has been performed varying the value of $v$ parameter in VIKOR method as shown in Figure 2. 
The restoration strategies are ranked by the values $S, R$ and $Q$, from the minimum value, resulting in three ranking lists as depicted in Table 5 . The best restoration strategy classified by the value of $Q$ is the compromise solution by consensus, provided that the conditions of acceptable advantage and stability are accomplished as follows:

- Acceptable advantage is achieved when $Q^{(2)}-Q^{(1)} \geq Q^{(J)}$; where $Q^{(2)}$ is the restoration strategy with second position in the ranking list by $Q, Q^{(1)}$ is the first one, and $Q^{(J)}=1 /(J-1)$, where $J$ is the number of strategies analyzed. For this case study, the positions of the restoration strategies cut-and-cover tunnel (CUT) and wildlife underpass strategies (WUN) are in closeness as shown in Table 5. Because of $Q^{(2)}-Q^{(1)}=0.2237 \geq Q^{(J)}=0.20$, the stability of the solution is accomplished.

- Acceptable stability is accomplished when the compromise solution is the best ranked by $Q$ and also by $S$ and/or $R$. As shown in Table 5 , the stability of the solution is accomplished by the restoration strategy cut-and-cover tunnel (CUT).

\section{Discussion}

This research work has introduced the implementation of environmental criteria in existing roadway networks assessment for restoring high cut slopes, developing a prioritization framework to help policy makers. Moreover, this hybrid procedure applied in restoration projects has proven to be a systematic and comprehensive technique to improve consensus as outlined before. The procedure ensures an equal treatment for all panelists with traceability and transparency. And, the compromise solution reached with the decision support system takes into account environmental criteria to reverse land degradation and fragmentation. The Delphi method has been used for assessing five criteria, eleven subcriteria and six different restoration strategies. This method ensures the efficiency of the multi-stake panel through the anonymous open-ended questionnaires to achieve consensus. The hierarchy structure analysis has played a key role to study the different objectives and threats. The restoration projects are analyzed with a hierarchical structure of four levels using the AHP technique. The measurement of the intangibles has been the crucial point for applying the AHP method. At the same time, it guarantees the consistency of the panelists' judgements through the evaluation of the CR. Finally, the VIKOR method has been performed in order to ensure consensus among the panelists, taking into account the two conditions of acceptable advantage and stability.

It is particularly interesting prioritize the different factors that are involved in the selection of the restoration strategies. These results provide evidence that road safety factor should be the main criteria to design the restoration projects. This result is not surprising, however, the biotic, abiotic environment and landform impact, as the most important components of the environmental impact indicator, must also be taken into consideration as a priority. The Figure 3 highlights that the functional and environmental criteria are the significant factors in the decision-making process of large cut slope restoration projects. In the studied case, as it is shown in Table 5, it has been found the adequacy and suitability of the cut-and-cover tunnels, despite their higher cost and complexity of its construction. It is well ranked according to VIKOR parameters, because cut-and-cover 
tunnel is the best ranked in S parameter, utility of the majority, and $\mathrm{R}$ parameter, individual reject. In second place by order of $Q$ parameter is the underpass constructive typology. This solution is the second ranked not only by $Q$, but also it is well positioned in both parameters $S$ and $R$. These kind of results do not appear in the rest of the analyzed strategies. On the other hand, rock outcrops generation has the most highlighted rejection parameter among the restoration projects under study. Unlike the conventional AHP procedure, which evaluates priorities for each of the studied strategies, the VIKOR technique reaches a stable solution with commitment among the consulted panelists. Both the stability condition as the condition of acceptable advantage have been satisfactorily accomplished. Moreover, the sensitivity analysis based on different values of $v$ parameter in VIKOR method from 0 to 1 have shown the stability of the consensus strategy (see Figure 2).

\section{Conclusion}

Nowadays, it is critical to improve existing European transport infrastructures in the context of the EU Strategy on Green Infrastructure. Developing green infrastructure is a key step to accomplish the goals of the EU 2020 Biodiversity Strategy. Environmental criteria as stated by EU strategy have not been considered in cut slopes restoration projects along European roadways. There is a lack of decision making frameworks to take into account environmental criteria in the selection of projects to restore high cut slopes using a panel of experts, and being effective in arriving at the best possible consensus strategy. The major difficulty has been achieving consensus using a panel of experts. The procedure gathers data from several panelists as the information will be more reliable than that of a single panelist. This framework improves the efficiency for building consensus among the panelists with traceability and transparency. The results indicate that a systematic decision-making procedure in the project conception phase can lead to a better consensual strategy with social and environmental acceptance. In addition, the panelists' consensual decision procedure is properly documented, unambiguous and verifiable. Finally, the decision support framework has been able to cope with environmental indicators together with territorial and economic indicators to reverse land degradation and fragmentation.

\section{References}

Bager A., Fontoura V., 2013. Evaluation of the effectiveness of a wildlife roadkill mitigation system in wetland habitat. Ecological Engineering 53, 31-38. DOI: 10.1016/j.ecoleng.2013.01.006.

Benítez-López A., Alkemade R., Verweij P.A., 2010. The impacts of roads and other infrastructure on mammal and bird populations: a meta-analysis. Biological Conservation 143 (6), 1307-1316. DOI: 10.1016/j.biocon.2010.02.009. 
Bortoleto L.A., Figueira C.J.M., Dunning J.B., Rodgers J., da Silva A.M., 2016. Suitability index for restoration in landscapes: An alternative proposal for restoration projects. Ecological Indicators 60, 724-735. DOI: 10.1016/j.ecolind.2015.08.002.

Calvi A., De Blasiis M.A., Guattari C. 2012. An empirical study of the effects of road tunnel on driving performance. Procedia - Social and Behavioral Sciences 53, 11001110. DOI: $10.1016 /$ j.sbspro.2012.09.959.

Canto-Perello J., Curiel-Esparza J., 2006. An analysis of utility tunnel viability in urban areas. Civil Engineering and Environmental Systems 23 (1), 11-19. DOI: 10.1080/10286600600562129.

Canto-Perello J., Curiel-Esparza J., Calvo V., 2009. Analysing utility tunnels and highway networks coordination dilemma. Tunnelling and Underground Space Technology 24 (2), 185-189. DOI: 10.1016/j.tust.2008.07.004.

Canto-Perello J., Martinez-Leon J., Curiel-Esparza J., Martin-Utrillas M., 2017, Consensus in prioritizing river rehabilitation projects through the integration of social, economic and landscape indicators. Ecological Indicators 72, 659-66. DOI: 10.1016/j.ecolind.2016.09.004.

Cervelli E., Pindozzi S., Sacchi M., Capolupo A., Cialdea D., Rigillo M., Boccia L., 2017. Supporting land use change assessment through Ecosystem Services and Wildlife Indexes. Land Use Policy 65, 249-265. DOI: 10.1016/j.landusepol.2017.04.011.

Costanza R., 2012. Ecosystem health and ecological engineering. Ecological Engineering 45, 24-29. DOI: 10.1016/j.ecoleng.2012.03.023.

Curiel-Esparza J., Gonzalez-Utrillas N., Canto-Perello J., Martin-Utrillas M., 2015. Integrating climate change criteria in reforestation projects using a hybrid decisionsupport system. Environmental Research Letters 10, 094022. DOI: 10.1088/17489326/10/9/094022.

Curiel-Esparza J., Mazario-Diez J.L., Canto-Perello J., Martin-Utrillas M., 2016. Prioritization by consensus of enhancements for sustainable mobility in urban areas. Environmental Science Policy 55 (1), 248-257. DOI: 10.1016/j.envsci.2015.10.015. 
Dong Y., Zhang G., Hong W., Xu Y., 2010. Consensus models for AHP group decision making under geometric mean priorization method. Decision Support Systems 49 (3), 281-289. DOI: 10.1016/j.dss.2010.03.003.

Dumbrovský M., Sobotková V., Šarapatka B., Chlubnac L., Váchalová R., 2014. Costeffectiveness evaluation of model design variants of broad-base terrace in soil erosion control. Ecological Engineering 68, 260-269. DOI: 10.1016/j.ecoleng.2014.03.082.

EEA European Environmental Agency 2011 Biodiversity. Available at: http://www.eea.europa.eu/soer-2015/europe/biodiversity\#tab-based-on-indicators

EUDirective 2014 Directive 2014/24/EU of the European Parliament and of the Council of 26 February 2014 on public procurement and repealing Directive 2004/18/EC

EUPAR European Parliament 2012 European Parliament resolution of 20 April 2012 on our life insurance, our natural capital: an EU biodiversity strategy to 2020 (2011/2307(INI)). Available at: http://ec.europa.eu/ environment/nature/ biodiversity/ comm2006/pdf/EP_resolution_april2012.pdf

Fu R., Guo Y., Yuan W., Feng H., Ma Y., 2011. The correlation between gradients of descending roads and accidents rates. Safety Science 49 (3), 416-423. DOI: 10.1016/j.ssci.2010.10.006.

Garg A., Tai K., Sreedeep S., 2014, Estimation of factor of safety of rooted slope using an evolutionary approach. Ecological Engineering 64, 314-324. DOI: 10.1016/j.ecoleng.2013.12.047.

Giri S., Nejadhashemi P., Woznicki S.A., 2016. Regulators' and stakeholders' perspectives in a framework for bioenergy development. Land Use Policy, Volume 59, 143-153. DOI: 10.1016/j.landusepol.2016.08.028.

Hu S.N., Fan Q.D., Hu Z.H., Xiao X.H., 2012 Applications of visual characteristics in highway alignment landscape design. Advanced Material Research 598, 260-263. DOI: 10.4028/www.scientific.net/AMR.598.260.

Hunt D.V.L, Rogers C.D.F., Jefferson I., 2013 Scenarios analysis through a futures performance framework. Proceedings of the Institution of Civil Engineers-Engineering Sustainability 166 (5), 258-271. DOI: 10.1680/ensu.12.00040. 
IENE - Infra Eco Network Europe Stering Committee 2013 From providing single fauna passages to reconciling green and transport infrastructure in Europe Technical meeting of the working group Habitat fragmentation caused by transport infrastructure. Ecological connectivity and transport routes, Cáceres Ministry for Agriculture, Food and Environmental Affairs of Spain. Available at: (http://www.magrama.gob.es/es/biodiversidad/temas/ecosistemas-yconectividad/jornadas_caceres_2013_8_sjolund_tcm7-309987.pdf)

luell B. et al 2003 Habitat Fragmentantion due to Transportation Infrastructure. Wildlife and traffic: A European Handbook for Identifying Conflicts and Designing Solutions European Co-operation in the Field of Scientific and Technical Research (COST): Brussels.

Laurila-Pant M., Lehikoinen A., Uusitalo L., Venesjärvi R., 2015. How to value biodiversity in environmental management?. Ecological Indicators 55, 1-11. DOI: 10.1016/j.ecolind.2015.02.034.

Lee J.W., Park C.M., Rhee H., 2013. Revegetation of decomposed granite roadcuts in Korea: developing digger, evaluating cost effectiveness, and determining dimensions of drilling holes, revegetation species, and mulching treatment. Land Degradation \& Development 24 (6), 591-604. DOI: 10.1002/ldr.2248.

Liu S.L., Cui B.S., Dong S.K., Yang Z.F., Yang M., Holt K., 2008. Evaluating the influence of road networks on landscape and regional ecological risk - A case study in Lacang River Valley of Southwest China. Ecological Engineering 34 (2), 91-99. DOI: 10.1016/j.ecoleng.2008.07.006.

Martin-Utrillas M., Juan-Garcia F., Canto-Perello J., Curiel-Esparza J., 2015. Optimal infrastructure selection to boost regional sustainable economy. International Journal of. Sustainable Development \& World Ecology 22 (1), 30-38. DOI: 10.1080/13504509.2014.954023.

Mata C., Hervás I., Herranz J., Suárez F., Malo J.E., 2008. Are motorway wildlife passages worth building? Vertebrate use of road-crossing structures on a Spanish motorway. Journal of Environment Management 88 (3), 407-415. DOI: 10.1016/j.jenvman.2007.03.014. 
Moreno-de las Heras M., Díaz-Sierra R., Nicolau J.M., Zavala M.A., 2011. Evaluating restoration of man-made slopes: a threshold approach balancing vegetation and rill erosion. Earth Surface Processes and Landforms 36 (10), 1367-1377. DOI: 10.1002/esp.2160.

Ng S.J., Dole J.W., Sauvajot R.M., Riley S.P.D., Valone T.J., 2004. Use of highway undercrossings by wildlife in southern California. Biological Conservation 115 (3), 499507. DOI: 10.1016/S0006-3207(03)00166-6.

Novakowski N., Wellar B., 2008. Using the Delphi technique in normative planning research: methodological design considerations. Environment and Planning A 40 (6), 1485-1500. DOI: 10.1068/a39267.

Olsson M.P.O., Widén P., Larkin J.L., 2008. Effectiveness of a highway overpass to promote landscape connectivity and movement of moose and roe deer in Sweden Landscape and Urban Planning 85 (2), 133-139. DOI: 10.1016/j.landurbplan.2007.10.006.

Opricovic S., 2009. A Compromise Solution in Water Resources Planning. Water Resources Management 23, 1549-1561. DOI: 10.1007/s11269-008-9340-y.

Opricovic S., Tzeng G.H., 2007. Extended VIKOR method in comparison with outranking methods. European Journal of Operational Research 178 (2), 514-529. DOI: 10.1016/j.ejor.2006.01.020.

Palmisano G.O., Loisi R.V., Ruggiero G., Rocchi L., Boggia A., Roma R., Dal Sasso P. 2016. Using Analytic Network Process and Dominance-based Rough Set Approach for sustainable requalification of traditional farm buildings in Southern Italy. Land Use Policy, 59 (31) 95-110. DOI: 10.1016/j.landusepol.2016.08.016.

Rajak S., Parthiban P., Dhanalakshmi R., 2016. Sustainable transportation systems performance evaluation using fuzzy logic. Ecological Indicators 71, 503-513. DOI: 10.1016/j.ecolind.2016.07.031.

Saaty T.L., 2008. Decision making with the analytic hierarchy process. International Journal of Services Sciences 1 (1), 83-98. DOI: 10.1504/IJSSCI.2008.017590.

Saaty T.L., 2012. Decision Making for Leaders: The Analytic Hierarchy Process for Decisions in a Complex World Rws Publications Pittsburgh. 
Shapira A., Shosany M., Nir-Goldenberg S., 2013. Combining analytical hierarchy process and agglomerative hierarchical clustering in search of expert consensus in Green Corridors development management. Environmental Management 52 (1), 123135. DOI: 10.1007/s00267-013-0064-2.

Sorolla A., Solina J., 2013. Structures to increase the permeability of roads on wildlife corridors in Catalonia. Habitat fragmentation caused by transport infrastructure. Ecological connectivity and transport routes, Cáceres. Ministry for Agriculture, Food and Environmental Affairs of Spain

Sun H.Y., Zhao Y., Shang Y.Q., Yu Y., Zhao Q.L., 2012. Deep-seated slope failures induced by inappropriate cutting in China. Rock Mechanics and Rock Engineering 45 (6), 1103-1311. DOI: 10.1007/s00603-012-0292-4.

Sun H.Y., Zhao Y., Shang Y.Q., Zhong J., 2013. Field measurement and failure forecast during the remediation of a failed cut slope. Environmental Earth Sciences 69 (7), 21792187. DOI: 10.1007/s12665-012-2046-8.

Tikkanen J., Hujala T., Kurttila M., 2016. Potentials of collaborative decision support methodologies to enhance reconciliation of competing forest uses - An action research on Regional Forest Programme in Finland. Land Use Policy 55, 61-72. DOI: 10.1016/j.landusepol.2016.03.021.

Tzoulas K., Korpela K., Venn S., Yli-Pelkonen V., Kaźmierczak A., Niemela J., James P., 2007. Promoting ecosystem and human health in urban areas using Green Infrastructure: A literature review. Landscape and Urban Planning 81(3), 167-178. DOI: 10.1016/j.landurbplan.2007.02.001.

Villalva P., Retob D., Santos-Reis M., Revilla E., Grilo C., 2013. Do dry ledges reduce the barrier effect of roads?. Ecological Engineering 57, 143-148. DOI: 10.1016/j.ecoleng.2013.04.005.

Yu D., Xun B., Shi P., Shao H., Liu Y., 2012. Ecological restoration planning based on connectivity in an urban area. Ecological Engineering 46, 24-33. DOI: 10.1016/j.ecoleng.2012.04.033. 
Table 1. Geometric mean value for the criteria and sub-criteria analyzed using a 9-point scale to perform pairwise comparisons Results for each expert

\section{Pairwise criteria}

1st 2nd 3rd 4th 5th 6th 7th 8th 9th 10th 11th 12th

Geometric

Mean

\begin{tabular}{|c|c|c|c|c|c|c|c|c|c|c|c|c|c|c|c|}
\hline Perceptual environment & vs. & Physical environment & $1 / 3$ & $1 / 3$ & $1 / 2$ & $1 / 3$ & $1 / 3$ & $1 / 4$ & $1 / 4$ & $1 / 2$ & $1 / 3$ & 2 & 2 & $1 / 3$ & 0.4581 \\
\hline Perceptual environment & vs. & Functional & 1 & $1 / 2$ & $1 / 9$ & $1 / 5$ & 1 & $1 / 8$ & $1 / 6$ & 2 & $1 / 5$ & 4 & 1 & 2 & 0.5485 \\
\hline Perceptual environment & vs. & Territorial & 1 & 1 & $1 / 4$ & 5 & 1 & $1 / 2$ & $1 / 8$ & 4 & 3 & 1 & 1 & 2 & 1.0538 \\
\hline Perceptual environment & vs. & Economical & 3 & 2 & $1 / 6$ & 3 & 1 & 1 & 4 & 3 & $1 / 3$ & 5 & 2 & 1 & 1.4901 \\
\hline Physical environment & vs. & Functional & 3 & 1 & $1 / 9$ & $1 / 3$ & 1 & $1 / 6$ & 2 & 3 & $1 / 3$ & 3 & 1 & 3 & 0.9124 \\
\hline Physical environment & vs. & Territorial & $1 / 2$ & 2 & $1 / 4$ & 7 & 3 & 4 & $1 / 2$ & 5 & 3 & 2 & 1 & 2 & 1.7111 \\
\hline Physical environment & vs. & Economical & 2 & 3 & $1 / 5$ & 5 & 2 & 3 & 4 & 4 & $1 / 3$ & 4 & 2 & 1 & 1.8429 \\
\hline Functional & vs. & Territorial & $1 / 2$ & 2 & 8 & 9 & 5 & 8 & 1 & 3 & 5 & $1 / 2$ & 1 & 1 & 2.2972 \\
\hline Functional & vs. & Economical & 1 & 2 & 6 & 7 & 4 & 6 & 8 & 2 & 3 & 1 & 1 & $1 / 2$ & 2.4569 \\
\hline Territorial & vs. & Economical & 3 & 1 & $1 / 3$ & $1 / 3$ & $1 / 4$ & 2 & 6 & $1 / 2$ & $1 / 3$ & 1 & 2 & 2 & 0.9666 \\
\hline
\end{tabular}

Pairwise sub-criteria

\begin{tabular}{|c|c|c|c|c|c|c|c|c|c|c|c|c|c|c|c|}
\hline Landform impact & vs. & Visual impact & 1 & 2 & 1 & 3 & 2 & 2 & 6 & 1 & 2 & 1 & 1 & 3 & 1.7567 \\
\hline Abiotic environment & vs. & Biotic environment & 5 & $1 / 3$ & $1 / 5$ & $1 / 3$ & $1 / 2$ & $1 / 4$ & 1 & 1 & $1 / 5$ & 2 & 1 & $1 / 2$ & 0.6123 \\
\hline Road safety & vs. & Users affection during construction & 1 & 4 & 6 & 3 & 4 & 4 & 8 & 1 & 5 & 3 & 2 & 2 & 3.0099 \\
\hline Territorial planning coordination & vs. & Horizontal occupation area & 1 & 1 & 7 & $1 / 3$ & 4 & 5 & 8 & $1 / 2$ & $1 / 3$ & $1 / 2$ & $1 / 3$ & $1 / 3$ & 1.1085 \\
\hline Territorial planning coordination & vs. & Ecosystem Fragmentation & $1 / 6$ & $1 / 3$ & 3 & 3 & 6 & 1 & 8 & $1 / 3$ & $1 / 3$ & $1 / 3$ & $1 / 3$ & $1 / 2$ & 0.8525 \\
\hline Horizontal occupation area & vs. & Ecosystem Fragmentation & $1 / 6$ & $1 / 3$ & $1 / 5$ & 5 & 2 & $1 / 4$ & 2 & $1 / 5$ & $1 / 3$ & $1 / 5$ & 1 & 1 & 0.5484 \\
\hline Construction costs & vs. & O\&M costs & 3 & 3 & 1 & 3 & $1 / 2$ & 2 & $1 / 8$ & 1 & $1 / 5$ & 2 & 2 & 2 & 1.1509 \\
\hline
\end{tabular}


Table 2. Average random consistency values (RCl) applied for consistency analysis in the AHP method (Saaty 2012)

\begin{tabular}{ccccccccccc}
\hline $\mathrm{n}$ & 1 & 2 & 3 & 4 & 5 & 6 & 7 & 8 & 9 & 10 \\
$\mathrm{RCl}$ & 0 & 0 & 0.52 & 0.89 & 1.11 & 1.25 & 1.35 & 1.40 & 1.45 & 1.49 \\
\hline
\end{tabular}


Table 3. Priority vector and consistency analysis of the pairwise comparison matrix for criteria applying the eigenvector method.

\begin{tabular}{ccccccc} 
& PEE & PHE & FUN & TEC & ECO & Priority vector \\
\hline PEE & 1.0000 & 0.4581 & 0.5485 & 1.0538 & 1.4901 & $\mathbf{0 . 1 5 6 4}$ \\
PHE & 2.1832 & 1.0000 & 0.9124 & 1.7111 & 1.8429 & $\mathbf{0 . 2 7 1 7}$ \\
FUN & 1.8233 & 1.0960 & 1.0000 & 2.2972 & 2.4569 & $\mathbf{0 . 3 0 3 0}$ \\
TEC & 0.9490 & 0.5844 & 0.4353 & 1.0000 & 0.9666 & $\mathbf{0 . 1 3 9 9}$ \\
ECO & 0.6711 & 0.5426 & 0.4070 & 1.0345 & 1.0000 & $\mathbf{0 . 1 2 9 1}$ \\
\hline$\lambda_{\max =5.0311}$ & $C l=0.0077$ & $C R=0.0069<0.1$ & & & &
\end{tabular}


Table 4. Priority vector and consistency analysis of the pairwise comparison matrix for the six alternatives with respect several sub-criteria applying the eigenvector method

\begin{tabular}{|c|c|c|c|c|c|c|c|}
\hline$L A$ & ROO & SBI & TER & WOV & WUN & CUT & Priority vector \\
\hline ROO & 1.0000 & 1.4066 & 0.8210 & 1.5020 & 1.1981 & 0.6996 & 0.1729 \\
\hline SBI & 0.7109 & 1.0000 & 0.8697 & 1.1677 & 1.1663 & 0.5887 & 0.1440 \\
\hline TER & 1.2181 & 1.1498 & 1.0000 & 1.2721 & 1.1608 & 0.5992 & 0.1683 \\
\hline WOV & 0.6658 & 0.8564 & 0.7861 & 1.0000 & 0.7596 & 0.5223 & 0.1214 \\
\hline WUN & 0.8347 & 0.8574 & 0.8614 & 1.3164 & 1.0000 & 0.5325 & 0.1408 \\
\hline CUT & 1.4294 & 1.6985 & 1.6690 & 1.9147 & 1.8779 & 1.0000 & 0.2527 \\
\hline$\lambda_{\max }=6.0238$ & $C l=0.0047$ & $C R=0.0038<0.1$ & & & & & \\
\hline VI & ROO & SBI & TER & WOV & WUN & CUT & Priority vector \\
\hline ROO & 1.0000 & 0.9295 & 0.9965 & 1.3733 & 1.1160 & 0.7109 & 0.1626 \\
\hline SBI & 1.0759 & 1.0000 & 0.7977 & 1.1611 & 1.0818 & 0.6983 & 0.1555 \\
\hline TER & 1.0035 & 1.2536 & 1.0000 & 1.1571 & 0.9791 & 0.6432 & 0.1606 \\
\hline WOV & 0.7282 & 0.8612 & 0.8642 & 1.0000 & 0.7037 & 0.4517 & 0.1214 \\
\hline WUN & 0.8960 & 0.9244 & 1.0213 & 1.4210 & 1.0000 & 0.5490 & 0.1517 \\
\hline CUT & 1.4067 & 1.4320 & 1.5547 & 2.2138 & 1.8216 & 1.0000 & 0.2481 \\
\hline$\lambda_{\max }=6.0239$ & $C l=0.0048$ & $C R=0.0038<0.1$ & & & & & \\
\hline$A B$ & ROO & SBI & TER & WOV & WUN & CUT & Priority vector \\
\hline
\end{tabular}




\begin{tabular}{cccccccc}
\hline ROO & 1.0000 & 1.0958 & 1.3347 & 2.0963 & 2.0458 & 1.1066 & 0.2190 \\
SBI & 0.9126 & 1.0000 & 1.4141 & 2.9676 & 2.3735 & 1.3652 & 0.2419 \\
TER & 0.7492 & 0.7072 & 1.0000 & 1.6331 & 1.3129 & 1.0957 & 0.1639 \\
WOV & 0.4770 & 0.3370 & 0.6123 & 1.0000 & 0.9999 & 0.7241 & 0.1022 \\
WUN & 0.4888 & 0.4213 & 0.7617 & 1.0001 & 1.0000 & 0.6674 & 0.1085 \\
CUT & 0.9037 & 0.7325 & 0.9127 & 1.3809 & 1.4984 & 1.0000 & 0.1646 \\
$\lambda_{\text {max }=6.0317}$ & Cl=0.0063 & CR=0.0051<0.1 & & & & & \\
\hline BI & ROO & SBI & TER & WOV & WUN & CUT & Priority vector \\
\hline ROO & 1.0000 & 1.5651 & 1.4422 & 0.9246 & 0.8432 & 0.8502 & 0.1783 \\
SBI & 0.6389 & 1.0000 & 1.3160 & 0.9614 & 0.8986 & 1.2165 & 0.1635 \\
TER & 0.6934 & 0.7599 & 1.0000 & 0.8281 & 0.6760 & 0.6708 & 0.1251 \\
WOV & 1.0816 & 1.0401 & 1.2076 & 1.0000 & 0.8408 & 0.8363 & 0.1632 \\
WUN & 1.1860 & 1.1128 & 1.4793 & 1.1893 & 1.0000 & 0.9582 & 0.1875 \\
CUT & 1.1762 & 0.8221 & 1.4907 & 1.1957 & 1.0436 & 1.0000 & 0.1824 \\
$\lambda_{\text {max }=6.0513}$ & $\mathrm{Cl}=0.0103$ & $\mathrm{CR}=0.0082<0.1$ & & & & & 0.1250 \\
\hline SA & $\mathrm{ROO}$ & $\mathrm{SBI}$ & $\mathrm{TER}$ & WOV & WUN & CUT & Priority vector \\
\hline ROO & 1.0000 & 0.9438 & 0.6835 & 0.7461 & 0.6222 & 0.6516 & 0.1250 \\
SBI & 1.0596 & 1.0000 & 0.8453 & 0.8872 & 0.7091 & 0.7490 & 0.1421
\end{tabular}




\begin{tabular}{|c|c|c|c|c|c|c|c|}
\hline TER & 1.4631 & 1.1830 & 1.0000 & 0.8872 & 0.7091 & 0.7490 & 0.1589 \\
\hline WOV & 1.3403 & 1.1271 & 1.1272 & 1.0000 & 0.9214 & 1.1496 & 0.1817 \\
\hline WUN & 1.6072 & 1.4101 & 1.4103 & 1.0853 & 1.0000 & 0.8538 & 0.1969 \\
\hline CUT & 1.5348 & 1.3351 & 1.3350 & 0.8699 & 1.1713 & 1.0000 & 0.1955 \\
\hline$\lambda_{\max }=6.0248$ & $\mathrm{Cl}=0.0050$ & $C R=0.0040<0.1$ & & & & & \\
\hline US & ROO & SBI & TER & WOV & WUN & CUT & Priority vector \\
\hline ROO & 1.0000 & 1.4282 & 1.5651 & 2.2329 & 1.6236 & 2.9938 & 0.2619 \\
\hline SBI & 0.7002 & 1.0000 & 1.4406 & 2.3915 & 2.0395 & 3.0590 & 0.2407 \\
\hline TER & 0.6389 & 0.6941 & 1.0000 & 1.9893 & 1.3083 & 2.3530 & 0.1801 \\
\hline WOV & 0.4479 & 0.4182 & 0.5027 & 1.0000 & 0.7790 & 1.0537 & 0.0996 \\
\hline WUN & 0.6159 & 0.4903 & 0.7643 & 1.2837 & 1.0000 & 1.4066 & 0.1321 \\
\hline CUT & 0.3340 & 0.3269 & 0.4250 & 0.9490 & 0.7109 & 1.0000 & 0.0856 \\
\hline$\lambda_{\max }=6.0359$ & $C l=0.0072$ & $C R=0.0057<0.1$ & & & & & \\
\hline$T E$ & ROO & SBI & TER & WOV & WUN & CUT & Priority vector \\
\hline ROO & 1.0000 & 0.7417 & 1.5131 & 0.9184 & 0.6586 & 0.5233 & 0.1345 \\
\hline SBI & 1.3482 & 1.0000 & 1.6189 & 1.0242 & 0.6414 & 0.6586 & 0.1578 \\
\hline TER & 0.6609 & 0.6177 & 1.0000 & 0.6586 & 0.4249 & 0.4260 & 0.0961 \\
\hline WOV & 1.0889 & 0.9764 & 1.5184 & 1.0000 & 0.6609 & 0.7606 & 0.1537 \\
\hline
\end{tabular}




\begin{tabular}{|c|c|c|c|c|c|c|c|}
\hline WUN & 1.5184 & 1.5590 & 2.3534 & 1.5132 & 1.0000 & 1.2115 & 0.2350 \\
\hline CUT & 1.9109 & 1.5184 & 2.3475 & 1.3147 & 0.8254 & 1.0000 & 0.2229 \\
\hline$\lambda_{\max }=6.0181$ & $\mathrm{Cl}=0.0036$ & $C R=0.0029<0.1$ & & & & & \\
\hline HO & ROO & SBI & TER & wOV & WUN & CUT & Priority vector \\
\hline ROO & 1.0000 & 0.7418 & 1.6031 & 0.7280 & 0.5919 & 0.7058 & 0.1345 \\
\hline SBI & 1.3480 & 1.0000 & 2.1097 & 0.8687 & 0.6961 & 1.1396 & 0.1788 \\
\hline TER & 0.6238 & 0.4740 & 1.0000 & 0.5722 & 0.3950 & 0.4797 & 0.0899 \\
\hline wov & 1.3737 & 1.1512 & 1.7477 & 1.0000 & 0.7241 & 0.8908 & 0.1760 \\
\hline WUN & 1.6894 & 1.4366 & 2.5314 & 1.3809 & 1.0000 & 1.3807 & 0.2401 \\
\hline CUT & 1.4167 & 0.8775 & 2.0847 & 1.1226 & 0.7243 & 1.0000 & 0.1807 \\
\hline$\lambda_{\max }=6.0154$ & $\mathrm{Cl}=0.0031$ & $C R=0.0025<0.1$ & & & & & \\
\hline$F R$ & ROO & SBI & TER & wov & WUN & CUT & Priority vector \\
\hline ROO & 1.0000 & 1.0243 & 1.1225 & 0.5083 & 0.4025 & 0.3243 & 0.0993 \\
\hline $\mathrm{SBI}$ & 0.9763 & 1.0000 & 1.2009 & 0.5973 & 0.6229 & 0.4324 & 0.1156 \\
\hline TER & 0.8909 & 0.8327 & 1.0000 & 0.4962 & 0.4122 & 0.3470 & 0.0930 \\
\hline wOV & 1.9675 & 1.6742 & 2.0152 & 1.0000 & 0.8380 & 0.5691 & 0.1843 \\
\hline WUN & 2.4846 & 1.6053 & 2.4259 & 1.1933 & 1.0000 & 0.8129 & 0.2213 \\
\hline CUT & 3.0837 & 2.3129 & 2.8815 & 1.7572 & 1.2302 & 1.0000 & 0.2865 \\
\hline
\end{tabular}




\begin{tabular}{|c|c|c|c|c|c|c|c|}
\hline$\lambda_{\max }=6.0192$ & $C l=0.0039$ & $C R=0.0031<0.1$ & & & & & \\
\hline co & ROO & SBI & TER & WOV & WUN & CUT & Priority vector \\
\hline ROO & 1.0000 & 2.0576 & 1.7567 & 3.3098 & 3.1536 & 4.0878 & 0.3340 \\
\hline SBI & 0.4860 & 1.0000 & 0.7672 & 2.4711 & 2.4711 & 2.8343 & 0.1993 \\
\hline TER & 0.5692 & 1.3034 & 1.0000 & 1.9039 & 1.6331 & 2.6377 & 0.1955 \\
\hline WOV & 0.3021 & 0.4047 & 0.5252 & 1.0000 & 0.8744 & 1.3732 & 0.0938 \\
\hline WUN & 0.3171 & 0.4047 & 0.6123 & 1.1436 & 1.0000 & 1.8961 & 0.1079 \\
\hline CUT & 0.2446 & 0.3528 & 0.3791 & 0.7282 & 0.5274 & 1.0000 & 0.0695 \\
\hline$\lambda_{\max }=6.0547$ & $C l=0.0109$ & $C R=0.0088<0.1$ & & & & & \\
\hline$O M$ & ROO & SBI & TER & WOV & WUN & CUT & Priority vector \\
\hline ROO & 1.0000 & 3.0862 & 1.7722 & 2.7513 & 2.7914 & 3.2617 & 0.3349 \\
\hline SBI & 0.3240 & 1.0000 & 0.6388 & 1.3222 & 1.4627 & 1.8069 & 0.1385 \\
\hline TER & 0.5643 & 1.5653 & 1.0000 & 2.4569 & 2.3888 & 2.8775 & 0.2293 \\
\hline WOV & 0.3635 & 0.7563 & 0.4070 & 1.0000 & 0.8744 & 1.7795 & 0.1093 \\
\hline WUN & 0.3582 & 0.6837 & 0.4186 & 1.1436 & 1.0000 & 1.6984 & 0.1117 \\
\hline CUT & 0.3066 & 0.5534 & 0.3475 & 0.5620 & 0.5888 & 1.0000 & 0.0763 \\
\hline$\lambda_{\max }=6.0612$ & $\mathrm{Cl}=0.0122$ & $C R=0.0098<0.1$ & & & & & \\
\hline
\end{tabular}


Table 5. Restoration strategies ranking sorted by $S, R$ and $Q$ obtained from VIKOR method applying a consensus strategy of maximum group utility

\begin{tabular}{|c|c|c|c|c|c|c|c|c|c|c|}
\hline \multirow[t]{2}{*}{ Subcriteria } & \multicolumn{3}{|c|}{ VIKOR parameters } & & \multicolumn{6}{|c|}{ Restoration strategies } \\
\hline & $f^{*}$ & f- & Wc & & ROO & SBI & TER & wov & WUN & CUT \\
\hline LA & 0.2527 & 0.1214 & 0.0997 & & 0.0606 & 0.0824 & 0.0640 & 0.0997 & 0.0849 & 0.0000 \\
\hline VI & 0.2481 & 0.1214 & 0.0567 & & 0.0383 & 0.0414 & 0.0392 & 0.0567 & 0.0432 & 0.0000 \\
\hline$A B$ & 0.2419 & 0.1022 & 0.1032 & & 0.0169 & 0.0000 & 0.0576 & 0.1032 & 0.0985 & 0.0570 \\
\hline BI & 0.1875 & 0.1251 & 0.1685 & & 0.0251 & 0.0649 & 0.1685 & 0.0658 & 0.0000 & 0.0138 \\
\hline SA & 0.1969 & 0.1250 & 0.2274 & & 0.2274 & 0.1734 & 0.1203 & 0.0481 & 0.0000 & 0.0045 \\
\hline US & 0.2619 & 0.0856 & 0.0756 & & 0.0000 & 0.0091 & 0.0351 & 0.0696 & 0.0556 & 0.0756 \\
\hline TE & 0.2350 & 0.0961 & 0.0448 & & 0.0324 & 0.0249 & 0.0448 & 0.0262 & 0.0000 & 0.0039 \\
\hline $\mathrm{HO}$ & 0.2401 & 0.0899 & 0.0361 & & 0.0254 & 0.0147 & 0.0361 & 0.0154 & 0.0000 & 0.0143 \\
\hline FR & 0.2865 & 0.0930 & 0.0589 & & 0.0570 & 0.0520 & 0.0589 & 0.0311 & 0.0198 & 0.0000 \\
\hline $\mathrm{CO}$ & 0.3340 & 0.0695 & 0.0691 & & 0.0000 & 0.0352 & 0.0362 & 0.0627 & 0.0591 & 0.0691 \\
\hline \multirow[t]{8}{*}{ OM } & 0.3349 & 0.0763 & 0.0600 & & 0.0000 & 0.0456 & 0.0245 & 0.0524 & 0.0518 & 0.0600 \\
\hline & & & & $S_{i}$ & 0.4830 & 0.5436 & 0.6853 & 0.6309 & 0.4129 & 0.2982 \\
\hline & & & & $\mathbf{R}_{\mathbf{i}}$ & 0.2274 & 0.1734 & 0.1685 & 0.1032 & 0.0985 & 0.0756 \\
\hline & & \multicolumn{2}{|c|}{$v=0.5$} & $\mathbf{Q}_{\mathrm{i}}$ & 0.7387 & 0.6391 & 0.8060 & 0.5207 & 0.2237 & 0.0000 \\
\hline & & & & Position: & 1 & 2 & 3 & 4 & 5 & 6 \\
\hline & & & & $S_{i}$ & CUT & WUN & ROO & $\mathrm{SBI}$ & WOV & TER \\
\hline & & & & $\mathbf{R}_{\mathbf{i}}$ & CUT & WUN & WOV & TER & $\mathrm{SBI}$ & ROO \\
\hline & & \multicolumn{2}{|c|}{$v=0.5$} & $Q_{i}$ & CUT & WUN & WOV & SBI & ROO & TER \\
\hline
\end{tabular}




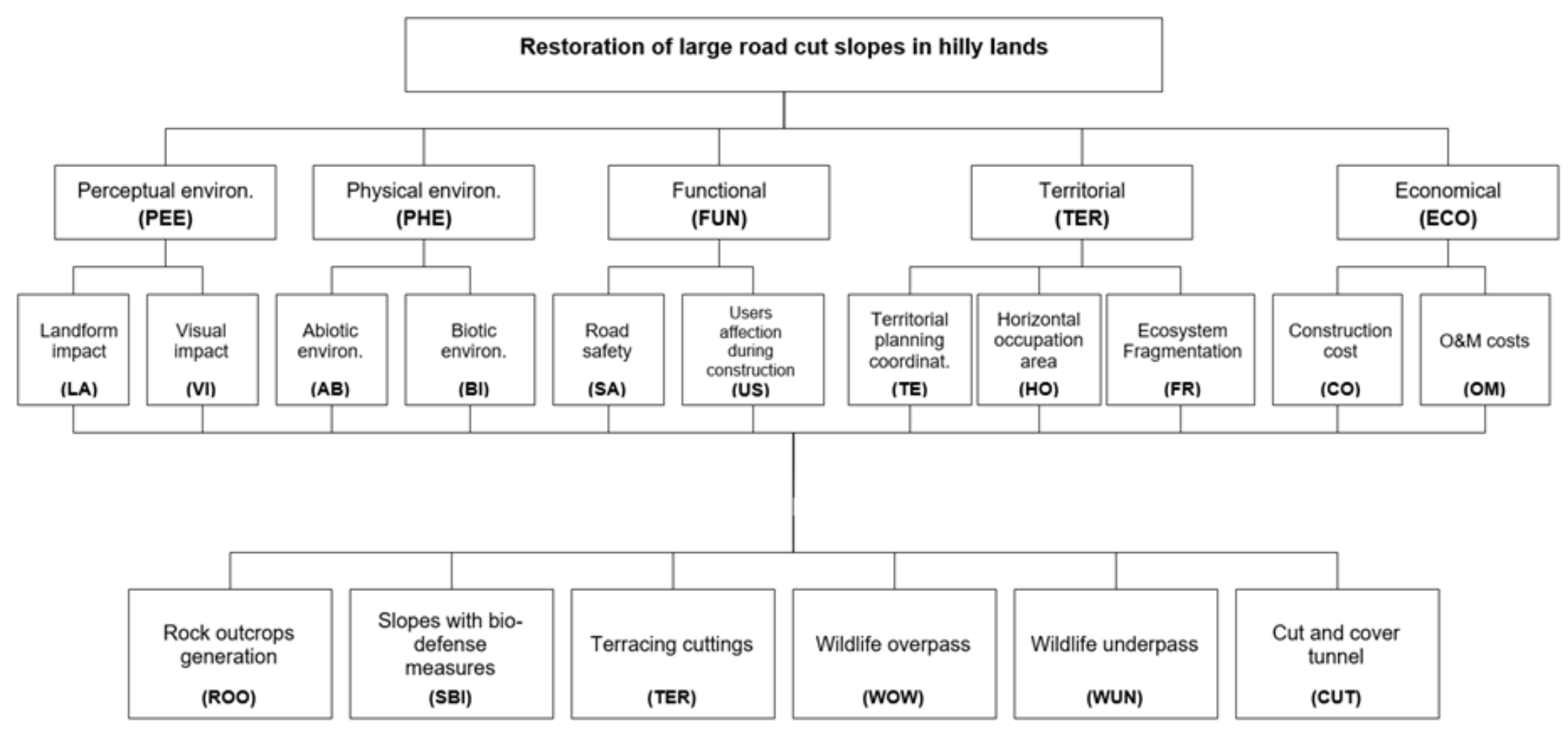

Figure 1. Four level hierarchy structure obtained from the elicitation technique applied to the panel of experts 


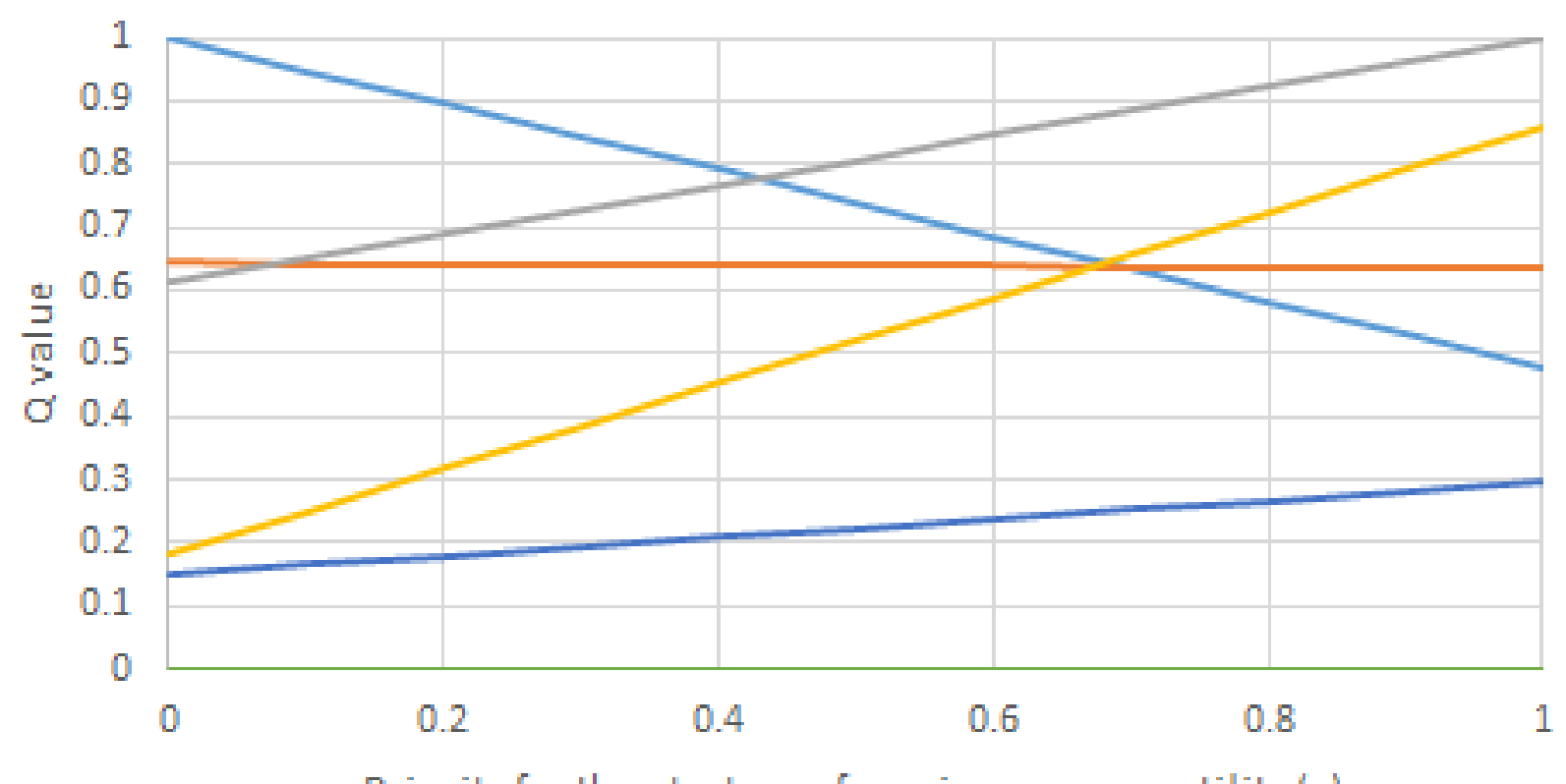

Priority for the strategy of maximum group utility $(v)$

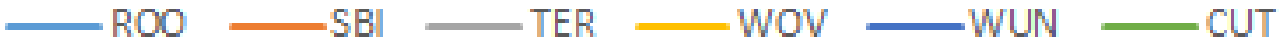

Figure 2. Sensitivity analysis of the changes in final results assessed based on different values of the priority for the strategy of maximum group utility $(v)$ parameter from 0 to 1 


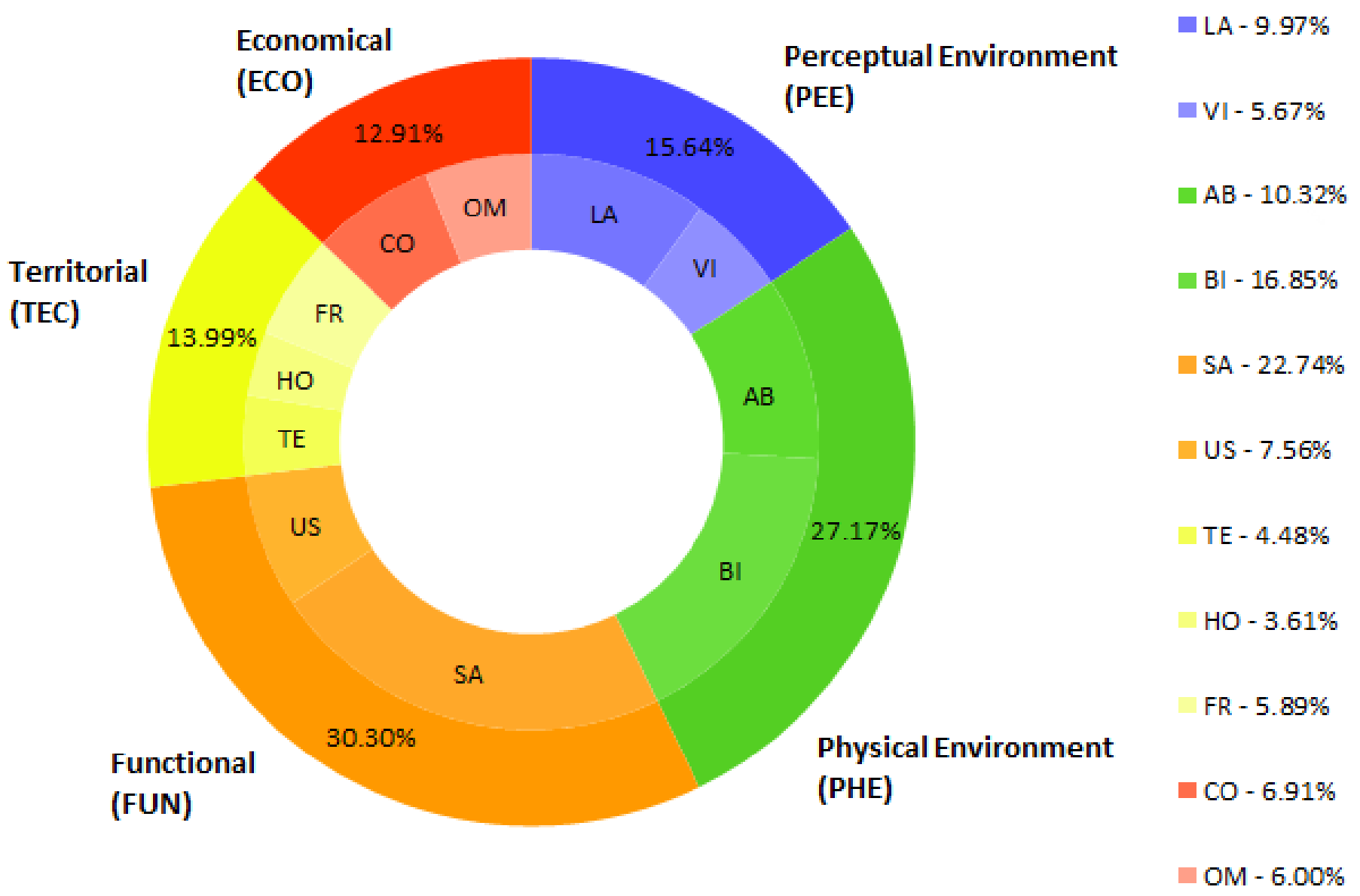

Figure 3. Obtained priorities for the considered criteria and sub-criteria from the hierarchy structure applied in the elicitation technique 